\title{
O PROGRAMA NACIONAL DE FORTALECIMENTO DA AGRICULTURA FAMILIAR (PRONAF) NO MATOPIBA ${ }^{1}$
}

\author{
César Nunes de Castro² \\ Rogério Edivaldo Freitas ${ }^{3}$ \\ Caroline Pereira Nascimento ${ }^{4}$
}

\section{INTRODUÇÃO}

No caso brasileiro, é conhecido o processo de expansão agrícola que se estendeu pelo eixo Sul-Centro-Oeste e adentrou áreas do Cerrado. Tal expansão perpassa pelos estados de Maranhão, Tocantins, Piauí e Bahia (Matopiba), com desdobramentos em ocupação de área da própria regiáo Norte. De acordo com Soterroni et al. (2016), essa área pode concentrar o futuro da expansão de grãos no Brasil até 2050, notabilizando-se rota específica de expansão de área agrícola que inclui leste de Tocantins, sul do Maranhão, sudoeste do Piauí e extremo oeste baiano.

Isto posto, analisar a agricultura familiar nos estados do Matopiba e as características dos agricultores familiares contratantes do Pronaf na região com base em dados do Censo Agropecuário 2017 (IBGE, 2019) constituem o objetivo deste estudo. Espera-se gerar uma avaliação que contribua para o conhecimento acumulado sobre o binômio agricultura familiar-Pronaf no Matopiba.

Com tal friso, o trabalho inclui as seguintes seções, além desta introdução. A seção 2 faz ilaçôes sobre o surgimento do Matopiba na expansão da fronteira agrícola brasileira. Já na 3 realiza-se uma análise exploratória da produção agropecuária da agricultura familiar no Matopiba a partir dos dados do Censo Agropecuário 2017. Na seção 4, são apresentadas especificidades do Pronaf no Matopiba. Por fim, a última seção oferece as consideraçôes finais.

\section{MATOPIBA NA EXPANSÃO DA FRONTEIRA AGRÍCOLA BRASILEIRA}

As projeções da Organização das Naçóes Unidas $(\mathrm{ONU})^{5}$ sinalizam para uma população global de 9,7 bilhóes de pessoas em 2050 e com simultâneos aumentos na demanda

\footnotetext{
1. DOI: http://dx.doi.org/10.38116/brua23art2

2. Especialista em políticas públicas na Diretoria de Estudos e Políticas Regionais, Urbanas e Ambientais (Dirur) do Ipea.

3. Técnico de planejamento e pesquisa na Dirur/lpea.

4. Pesquisadora do Programa de Pesquisa para o Desenvolvimento Nacional (PNPD) na Dirur/lpea.

5. Disponível em: <https://population.un.org/wpp/Download/Standard/Population/>. Acesso em: 10 out. 2019.
} 
mundial de alimentos, em especial nos países em desenvolvimento. Tal cenário coloca a oferta global de alimentos no centro das preocupaçôes do século XXI. Ao mesmo tempo, grandes produtores agropecuários (Rússia, Estados Unidos, Argentina, Austrália, Canadá e os membros da União Europeia) já estão no limite de espaço aproveitável para a expansão da área agrícola em condiçôes técnicas e/ou economicamente viáveis.

Por certo, o desenvolvimento agrícola tem determinantes geográficos claros, ancorados não raro nas grandes diferenças regionais existentes no comportamento do clima. Elementos náo diretamente observáveis ou mensurados, como a qualidade do solo ou o grau de avanço da tecnologia agrícola adotada, também são fatores importantes (Moreira e Paez, 2003). De modo geral, a distribuição do crescimento de área utilizada entre diferentes regiōes decorre da aptidáo agrícola dos respectivos solos e da adaptabilidade das distintas culturas às condiçôes edafoclimáticas de cada região (Mello, 1990). Também, o perfil de ocupação de novas áreas é função das condicionantes tecnológicas presentes e da rentabilidade relativa de certa produção. Dado certo nível efetivo de ocupação de área, as fronteiras disponíveis serão incorporadas com base na tecnologia disponível e na rentabilidade de uma atividade diante das demais.

A primeira variável, a base tecnológica disponível, deriva da estrutura de pesquisa já montada ou importável e do aparato regulatório que controla as novas pesquisas associadas a cada produção agrícola. Já a rentabilidade de uma dada cultura associa-se fundamentalmente à performance recente de seus preços, aos cenários a eles atrelados e à estrutura de produção e comercialização (doméstica, doméstica e externa, externa) de cada produto. Com isso, a rentabilidade relativa entre as culturas é função basicamente das tecnologias específicas (disponíveis ou importáveis) e das variáveis econômicas que afetam a rentabilidade das respectivas atividades concorrentes.

Particularmente num país com as dimensóes do Brasil, sob tais condicionantes, as experiências regionais necessariamente se apresentarão de forma bastante heterogênea. No caso dos cerrados brasileiros, por exemplo, é sabido que parte da dinâmica observada foi e é também explicada por políticas governamentais. Neste leque enquadram-se o crédito para a produção e a comercialização agrícolas; políticas de preços mínimos (sobretudo nas décadas de 1970 e 1980); investimentos na pesquisa agrícola; e a disseminação de novas tecnologias, (principalmente a partir da criação da Empresa Brasileira de Pesquisa Agropecuária Embrapa), particularmente importantes para a agricultura da regiáo Centro-Oeste (Castro, 2003). Não por acaso, a produção de grãos cresceu mais rapidamente no Centro-Oeste que nas demais regiōes.

O Sul do país, em contrapartida, constituiu-se em uma regiấo estabelecida já anteriormente à expansão do Centro-Oeste e buscou se adaptar à perda de subsídios e à intensa competição com as importaçôes resultantes da liberalização comercial decorrente da formaçáo do Mercado Comum do Sul (Mercosul), substancialmente mais integrado no que se refere ao comércio agrícola. Por fim, o Nordeste parece ser menos afetado pelas reformas de políticas e pelo ambiente econômico, sobretudo por conta dos elevados custos de transações, que resultam da distância e da infraestrutura local menos densa. ${ }^{6}$

6. Para uma observação mais precisa dos êxitos, desafios e opções de política no caso do Nordeste brasileiro, vejam-se Castro (2019), Sobel e Xavier (2019), Nobre et al. (2019), Freitas (2019) e Alves et al. (2019), que discutem as políticas de agricultura irrigada e de energia fotovoltaica praticadas ou à disposição daquela região, bem como a inserção do Pronaf no Semiárido. 
Grosso modo, além das condiçôes iniciais desfavoráveis de distribuição da terra, o Brasil apresenta pelo menos dois polos que contribuem para o agravamento da diferença entre as regióes na agricultura: o Nordeste, que em parte manteve suas características seculares e ainda procura consolidar um sistema produtivo plenamente capaz de enfrentar a seca, e o Centro-Oeste, com um notável potencial produtivo, mas altamente concentrador de renda, devido às condiçôes naturais favoráveis e incorporadas ao desenvolvimento e à consolidação da agricultura de larga escala.

A razão principal da vantagem do Centro-Oeste, em termos de ganhos relativos de aptidão agrícola, com a adoção de alta tecnologia, encontra-se na maior adequação do solo local à mecanização agrícola, em razão de suas terras serem planas. Em boa medida, as mudanças tecnológicas que viabilizaram a incorporação produtiva dos cerrados, a existência de terras planas e mais baratas, o avanço da infraestrutura, especialmente transportes, e a maior produtividade física por área dinamizaram a fronteira do Centro-Oeste. Neste contexto, segundo Bolfe et al. (2016), o aumento da produção de soja e milho em áreas de fronteira agrícola nos estados do Matopiba está relacionado à expansão tanto sobre áreas previamente antropizadas quanto das antropizadas mais recentemente, depois de 2002.

\section{PRODUÇÃO AGROPECUÁRIA DA AGRICULTURA FAMILIAR NO MATOPIBA EM 2017: BREVE DIAGNÓSTICO A PARTIR DOS DADOS DO CENSO AGROPECUÁRIO DE 2017}

Em anos recentes, com o crescimento do interesse sobre a região do Matopiba, muitas pesquisas foram realizadas com o intuito de gerar conhecimento sobre a regiáo sob múltiplos arcabouços analíticos e com enfoques variados. Frequentemente, entretanto, o enfoque recai sobre a atividade agropecuária regional como um todo, sem se ter por objetivo de investigação a realidade da atividade agrícola sob enfoque por perfil de empreendimento agrícola, como a agricultura familiar.

Nesse sentido reside a contribuição deste estudo - a partir dos dados do Censo Agropecuário 2017 (IBGE, 2019), apresentar um diagnóstico da agricultura familiar nesse recorte territorial. Os municípios que compóem o Matopiba possuem 289.943 estabelecimentos agropecuários, dos quais 231.943 são da agricultura familiar, sendo 44.912 na Bahia, 124.728 no Maranhão, 17.348 no Piauí e 44.955 em Tocantins.

No conjunto, aproximadamente $79 \%$ dos estabelecimentos agropecuários da região são enquadrados na categoria de produção familiar, ao passo que no Brasil essa relação é de aproximadamente $76 \%$. No interior da região, a maior ou menor presença relativa da agricultura familiar, entretanto, é bastante variável. Enquanto em Luzinópolis (Tocantins) $92 \%$ dos estabelecimentos são do tipo familiar, em Lizarda (Tocantins) apenas 30\% fazem parte dessa categoria. Enquanto em Belágua (Maranhão) 97\% dos estabelecimentos são familiares, em Luís Eduardo Magalhães (Bahia) apenas 41\% dos estabelecimentos o são.

Com relação à produção desses estabelecimentos, como é frequente no caso da agricultura familiar, a maioria realiza atividades de produção variadas, envolvendo a criação animal e a produção vegetal em um mesmo estabelecimento. Nas tabelas 1 e 2, são apresentados os valores totais da produçáo animal e vegetal da agricultura familiar da região.

O valor da produção animal dos agricultores familiares do Matopiba (tabela 1) concentra-se em animais de grande porte (principalmente bovinos), com participação de aproximadamente $88 \%$ do valor total da produção animal dos 337 municípios que compóem 
a regiấo. A especialização na produção de animais de grande porte é particularmente evidente no estado de Tocantins.

TABELA 1

Matopiba: valor total da produção animal por tipo de produção, segundo a agricultura familiar (2017) (Em R\$1 mil)

\begin{tabular}{|c|c|c|c|c|c|}
\hline Categoria & Bahia & Maranhão & Piauí & Tocantins & Total do Matopiba \\
\hline Animal de grande porte & 234.342 & 592.081 & 63.309 & 711.473 & 1.601 .205 \\
\hline Animal de médio porte & 6.387 & 29.311 & 5.015 & 9.919 & 50.632 \\
\hline Animal de pequeno porte & 2.412 & 11.301 & 328 & 2.433 & 16.474 \\
\hline Aves & 23.850 & 45.134 & 9.311 & 64.079 & 142.374 \\
\hline
\end{tabular}

Fonte: IBGE (2019).

Com relação à produção vegetal, seu valor se concentra em espécies temporárias, como soja, milho, algodão e outras (categoria lavouras temporárias na tabela 2). O resultado do valor da produção de produtos provenientes de extração vegetal constitui a segunda categoria de maior valor de produção vegetal da agricultura familiar da região.

TABELA 2

Matopiba: valor total da produção vegetal por tipo de produção, segundo a agricultura familiar (2017) (Em R\$ 1 mil)

\begin{tabular}{lccrrr}
\hline Categoria & Bahia & Maranhão & Piauí & Tocantins & Total do Matopiba \\
\hline Lavouras permanentes & 54.005 & 15.314 & 817 & 7.929 & $\mathbf{7 8 . 0 6 5}$ \\
Lavouras temporárias & 63.251 & 346.045 & 42.719 & 216.662 & $\mathbf{6 6 8 . 6 7 7}$ \\
Horticultura & 6.847 & 12.005 & 1.027 & 16.532 & $\mathbf{3 6 . 4 1 1}$ \\
Extração vegetal & 8.319 & 74.184 & 5.456 & 10.634 & $\mathbf{9 8 . 5 9 3}$ \\
\hline
\end{tabular}

Fonte: IBGE (2019).

Com relação às receitas dos estabelecimentos e dos produtores rurais, as fontes são diversas. As principais, em termos de valor, são apresentadas na tabela 3. No Matopiba, as receitas provenientes da pecuária e dos derivados da produção animal constituem a principal fonte em termos de valor agregado. Na sequência, os recursos provenientes de aposentadorias e pensóes e, em terceiro lugar, da venda de produtos de origem vegetal.

TABELA 3

Matopiba: valor da receita por tipo das principais receitas do estabelecimento, segundo a agricultura familiar (2017)

(Em R\$ 1 mil)

\begin{tabular}{|c|c|c|c|c|c|}
\hline Categoria & Bahia & Maranhão & Piauí & Tocantins & Total do Matopiba \\
\hline Produção do estabelecimento - produtos vegetais & 82.876 & 131.418 & 9.438 & 161.434 & 385.166 \\
\hline Produção do estabelecimento - animais e produtos derivados & 243.745 & 621.422 & 53.487 & 675.715 & 1.594 .369 \\
\hline Produção do estabelecimento - produtos da agroindústria & 22.596 & 74.017 & 4.313 & 38.322 & 139.248 \\
\hline Receitas do produtor - recursos de aposentadorias ou pensões & 277.873 & 508.604 & 122.617 & 228.774 & 1.137 .868 \\
\hline $\begin{array}{l}\text { Receitas do produtor - rendas obtidas em atividades } \\
\text { fora do estabelecimento }\end{array}$ & 21.120 & 35.353 & 8.414 & 49.521 & 114.408 \\
\hline $\begin{array}{l}\text { Receitas provenientes de programas dos governos (federal, } \\
\text { estadual ou municipal) }\end{array}$ & 34.228 & 114.549 & 15.011 & 8.083 & 171.871 \\
\hline
\end{tabular}

Fonte: IBGE (2019). 
As receitas provenientes de programas governamentais (federal, estadual ou municipal) constituem uma fonte significativa, particularmente nos estados de Maranhão (8\%) e Piauí (7\%). No Piauí, essas receitas constituem a terceira principal fonte, depois das receitas de produção animal e produtos derivados e das aposentadorias e pensóes.

Quanto às despesas dos estabelecimentos dos agricultores familiares da região, elas são apresentadas nas tabelas 4 e 5 . Na tabela 4 , as despesas são demonstradas de acordo com os seus valores nominais (em reais de 2017) e, na tabela 5, de acordo com a participação (em porcentagem) da despesa com relaçáo à despesa total.

No geral, os três principais gastos são com compra de animais, compra de sal, ração e outros insumos para a criaçáo animal e salários. Das três principais fontes de despesa, duas se relacionam com a criação animal, novamente evidenciando sua importância para a agricultura familiar. Entre outros motivos, essa ênfase conferida aos pequenos agricultores à produção animal e à posse de cabeças de gado reveste-se no fato de constituição de reserva de valor, a ser utilizada com diferentes finalidades (obter recurso financeiro para saldar dívidas, adquirir terra, investir em novos equipamentos, financiar projetos pessoais etc.) em momentos oportunos.

Por certo, há diferenças na composição dos gastos dos agricultores familiares do Matopiba. Caso se avaliasse a composiçáo desses gastos de forma individualizada, os gastos nos diferentes itens apresentados nas tabelas 4 e 5 seriam significativamente diferentes em função do grau de especialização do agricultor (produção animal ou vegetal etc.), do padrão tecnológico da atividade produtiva do estabelecimento, da escala de produção, entre outros fatores.

TABELA 4

Matopiba: estabelecimentos e valor da despesa por tipo, segundo a agricultura familiar (2017) (Em R\$ 1 mil)

\begin{tabular}{lrrrrr}
\hline Categoria & \multicolumn{1}{c}{ Bahia } & Maranhão & Piauí & Tocantins & Total do Matopiba \\
\hline Arrendamento de terras & 8.152 & 6.386 & 3.181 & 9.793 & $\mathbf{2 7 . 5 1 2}$ \\
Contratação de serviços & 5.898 & 15.328 & 1.755 & 11.535 & $\mathbf{3 4 . 5 1 6}$ \\
Salários pagos & 35.037 & 78.793 & 10.973 & 88.192 & $\mathbf{2 1 2 . 9 9 5}$ \\
Adubos e corretivos & 32.016 & 14.032 & 1.986 & 34.872 & $\mathbf{8 2 . 9 0 6}$ \\
Sementes e mudas & 4.471 & 16.715 & 1.259 & 16.858 & $\mathbf{3 9 . 3 0 3}$ \\
Compra de animais & 36.669 & 97.766 & 10.523 & 109.418 & $\mathbf{2 5 4 . 3 7 6}$ \\
Agrotóxicos & 10.508 & 23.017 & 1.027 & 29.777 & $\mathbf{6 4 . 3 2 9}$ \\
Medicamentos para animais & 9.918 & 40.913 & 3.598 & 28.860 & $\mathbf{8 3 . 2 8 9}$ \\
Sal, ração e outros suplementos & 58.215 & 79.557 & 10.843 & 92.501 & $\mathbf{2 4 1 . 1 1 6}$ \\
Transporte da produção & 1.336 & 4.102 & 396 & 5.055 & $\mathbf{1 0 . 8 8 9}$ \\
Energia elétrica & 24.059 & 59.998 & 9.171 & 40.934 & $\mathbf{1 3 4 . 1 6 2}$ \\
Compra de máquinas e veículos & 2.458 & 6.608 & 1.443 & 11.709 & $\mathbf{2 2 . 2 1 8}$ \\
Combustíveis e lubrificantes & 19.552 & 44.403 & 12.535 & 63.628 & $\mathbf{1 4 0 . 1 1 8}$ \\
Novas culturas permanentes e silvicultura & 27.0 & 30.0 & 0.0 & 1.0 & $\mathbf{5 8 . 0}$ \\
Formação de pastagens & 14.472 & 29.673 & 3.139 & 27.142 & $\mathbf{7 4 . 4 2 6}$ \\
Outras despesas & 23.553 & 42.710 & 11.042 & 34.102 & $\mathbf{1 1 1 . 4 0 7}$ \\
Total & $\mathbf{2 8 6 . 3 4 1}$ & $\mathbf{5 6 0 . 0 3 1}$ & $\mathbf{8 2 . 8 7 1}$ & $\mathbf{6 0 4 . 3 7 7}$ & $\mathbf{1 . 5 3 3 . 6 2 0}$ \\
\hline
\end{tabular}

Fonte: IBGE (2019)

Essa avaliação individualizada não é realizada neste estudo, mas de posse das informaçôes apresentadas, agregadas por estado componente do Matopiba, é possível fazer algumas 
consideraçóes. No caso da compra de animais, por exemplo, os agricultores familiares da Bahia e do Piauí apresentam um padráo de gasto semelhante (quase 13\%), o mesmo podendo ser afirmado para os estados do Maranhão e do Tocantins (perto de 18\%) (tabela 5). Tal fato constitui indício do maior grau de especialização na produção animal dos agricultores familiares do Tocantins e do Maranhão com relação aos da Bahia e do Piauí; no caso do Tocantins, isso já havia sido observado quando da análise dos dados da tabela 1 .

$\mathrm{Na}$ Bahia, um gasto que chama a atenção relaciona-se ao dispêndio com adubos e corretivos. Enquanto os gastos médios dos estabelecimentos (tabela 5) dos outros estados componentes do Matopiba com esse item variam de 2,4\% (Piauí) a 5,77\% (Tocantins), na Bahia esse gasto se eleva para, em média, $11,18 \%$ dos gastos, indício da concentração de lavouras de culturas temporárias de elevada produtividade em alguns municípios do estado (Luís Eduardo Magalhães, Barreiras etc.).

Outra informação que merece ser mais bem investigada em outros estudos é o gasto proporcionalmente elevado com combustíveis e lubrificantes no Piauí. Enquanto nos estabelecimentos familiares da Bahia esse gasto representa, em média, 6,83\% do gasto total da propriedade, no Piauí representa 15,13\% (tabela 5). O mesmo comentário se aplica, também no caso do Piauí, com relação ao item de gasto outras despesas, significativamente mais elevado nos estabelecimentos desse estado que nos outros componentes do Matopiba.

TABELA 5

Matopiba: relação da despesa, por tipo, com a despesa total dos estabelecimentos familiares (2017) (Em \%)

\begin{tabular}{|c|c|c|c|c|}
\hline Categoria receita & Bahia & Maranhão & Piauí & Tocantins \\
\hline Arrendamento de terras & 2,85 & 1,14 & 3,84 & 1,62 \\
\hline Contratação de serviços & 2,06 & 2,74 & 2,12 & 1,91 \\
\hline Salários pagos & 12,24 & 14,07 & 13,24 & 14,59 \\
\hline Adubos e corretivos & 11,18 & 2,51 & 2,40 & 5,77 \\
\hline Sementes e mudas & 1,56 & 2,98 & 1,52 & 2,79 \\
\hline Compra de animais & 12,81 & 17,46 & 12,70 & 18,10 \\
\hline Agrotóxicos & 3,67 & 4,11 & 1,24 & 4,93 \\
\hline Medicamentos para animais & 3,46 & 7,31 & 4,34 & 4,78 \\
\hline Sal, ração e outros suplementos & 20,33 & 14,21 & 13,08 & 15,31 \\
\hline Transporte da produção & 0,47 & 0,73 & 0,48 & 0,84 \\
\hline Energia elétrica & 8,40 & 10,71 & 11,07 & 6,77 \\
\hline Compra de máquinas e veículos & 0,86 & 1,18 & 1,74 & 1,94 \\
\hline Combustíveis e lubrificantes & 6,83 & 7,93 & 15,13 & 10,53 \\
\hline Novas culturas permanentes e silvicultura & 0,01 & 0,01 & 0,00 & 0,01 \\
\hline Formação de pastagens & 5,05 & 5,30 & 3,79 & 4,49 \\
\hline Outras despesas & 8,23 & 7,63 & 13,32 & 5,64 \\
\hline Total & 100,00 & 100,00 & 100,00 & 100,00 \\
\hline
\end{tabular}

Fonte: IBGE (2019).

\section{PRONAF NO MATOPIBA: ESPECIFICIDADES}

Nesta seção, serão analisadas algumas características gerais dos agricultores familiares participantes do Pronaf na região do Matopiba, de acordo com dados do Censo Agropecuário 2017. A grande maioria dos agricultores familiares nos municípios do Matopiba é participante do Pronaf - destes, a maior parte participa do Pronaf B (tabela 6). 
TABELA 6

Matopiba: estabelecimentos pronafianos (B e V) (2017)

\begin{tabular}{lccc}
\hline Unidade da Federação (UF) & Estabelecimentos de agricultura familiar & Pronaf B & Pronaf $\mathrm{V}$ \\
\hline Bahia & 44.912 & 39.217 & 5.653 \\
Maranhão & 124.728 & 109.288 & 15.340 \\
Piauí & 17.348 & 15.281 & 2.058 \\
Tocantins & 44.955 & 29.164 & 15.580 \\
Total do Matopiba & $\mathbf{2 3 1 . 9 4 3}$ & $\mathbf{1 9 2 . 9 5 0}$ & $\mathbf{3 8 . 6 3 1}$ \\
\hline
\end{tabular}

Fonte: IBGE (2019).

O valor da produção animal dos estabelecimentos familiares do Matopiba crediários do Pronaf é apresentado na tabela 7. Ao comparar esses dados com aqueles exibidos na tabela 2 (valor da produçáo animal de todos os estabelecimentos agropecuários familiares do Matopiba), percebe-se como parte significativa da produção animal, em todas as categorias, dos agricultores familiares do Matopiba é proveniente de estabelecimentos que receberam crédito do Pronaf.

Do valor total da produçáo de animais de grande, médio e pequeno porte e de aves dos agricultores familiares do Matopiba, aproximadamente 64\%, 82\%, 37\% e 74\% são obtidos de estabelecimentos pronafianos. Apesar de a maioria dos estabelecimentos fazer parte do Pronaf $\mathrm{B}$, a maior parte do valor da produçáo animal, apresentado anteriormente na tabela 1, é realizada por estabelecimentos do Pronaf V.

TABELA 7

Matopiba: valor total da produção animal por tipo, segundo a agricultura familiar pronafiana (2017) (Em R\$ 1 mil)

\begin{tabular}{lcrrrrr}
\hline Categoria & Categoria da agricultura familiar & Bahia & Maranhão & Piauí & Tocantins & Total do Matopiba \\
\hline \multirow{2}{*}{ Animal de grande porte } & Pronaf B & 94.229 & 119.911 & 26.255 & 101.080 & $\mathbf{3 4 1 . 4 7 5}$ \\
& Pronaf V & 47.080 & 260.315 & 31.492 & 352.516 & $\mathbf{6 9 1 . 4 0 3}$ \\
\hline \multirow{2}{*}{ Animal de médio porte } & Pronaf B & 2.410 & 14.698 & 2.009 & 1.934 & $\mathbf{2 1 . 0 5 1}$ \\
& Pronaf V & 1.846 & 9.341 & 2.392 & 7.105 & $\mathbf{2 0 . 6 8 4}$ \\
\hline \multirow{2}{*}{ Animal de pequeno porte } & Pronaf B & 127 & 1.080 & 70 & 45 & $\mathbf{1 . 3 2 2}$ \\
& Pronaf V & 341 & 3.524 & 168 & 823 & $\mathbf{4 . 8 5 6}$ \\
\hline \multirow{2}{*}{ Aves } & Pronaf B & 15.685 & 25.202 & 6.335 & 21.160 & $\mathbf{6 8 . 3 8 2}$ \\
& Pronaf V & 3.390 & 10.757 & 2.663 & 21.046 & $\mathbf{3 7 . 8 5 6}$ \\
\hline
\end{tabular}

Fonte: IBGE (2019).

Com relação à produção vegetal, os dados são apresentados na tabela 8 . No caso das lavouras permanentes, em todos os estados da regiâo, o valor da produção das lavouras permanentes em 2017 foi concentrado entre os agricultores familiares crediários do Pronaf V, especialmente no caso da Bahia. Dada a característica das lavouras permanentes de variabilidade de produção, e consequentemente de renda, em funçáo dos ciclos produtivos mais ou menos longos (ao contrário das lavouras temporárias, em que o ciclo produtivo limita-se a alguns meses), os agricultores familiares que investem mais em lavouras permanentes possuem a tendência de ter uma renda mais variável que aqueles que investem em lavouras temporárias; não surpreende, portanto, que esses agricultores recorram mais ao Pronaf V, modalidade destinada a famílias de pequenos agricultores com renda variável.

No caso das lavouras temporárias, contrariamente, boa parte do valor da produçáo dos agricultores familiares pronafianos do Matopiba nos estados de Bahia, Maranhão e Piauí 
concentra-se entre aqueles enquadrados no Pronaf B, com exceção do Tocantins. No caso da produção hortícola e do extrativismo vegetal, seu valor está mais igualmente distribuído entre os agricultores familiares participantes das duas modalidades do Pronaf, com exceçáo do valor da produção hortícola no Piauí e no Tocantins e do extrativismo vegetal na Bahia.

TABELA 8

Matopiba: valor total da produção vegetal por tipo, segundo a agricultura familiar pronafiana (2017) (Em R\$ 1 mil)

\begin{tabular}{lcrrrrr}
\hline Categoria & Categoria da agricultura familiar & Bahia & Maranhão & \multicolumn{1}{c}{ Piauí } & Tocantins & Total do Matopiba \\
\hline \multirow{2}{*}{ Lavouras permanentes } & Pronaf B & 373 & 6.525 & 110 & 1.013 & $\mathbf{8 . 0 2 1}$ \\
& Pronaf V & 46.595 & 14.125 & 308 & 4.921 & $\mathbf{6 5 . 9 4 9}$ \\
\hline \multirow{2}{*}{ Lavouras temporárias } & Pronaf B & 25.688 & 219.773 & 19.267 & 29.684 & $\mathbf{2 9 4 . 4 1 2}$ \\
& Pronaf V & 14.291 & 70.352 & 12.448 & 76.356 & $\mathbf{1 7 3 . 4 4 7}$ \\
\hline \multirow{2}{*}{ Horticultura } & Pronaf B & 1.372 & 4.480 & 272 & 2.033 & $\mathbf{8 . 1 5 7}$ \\
& Pronaf V & 1.649 & 5.852 & 509 & 9.129 & $\mathbf{1 7 . 1 3 9}$ \\
\hline \multirow{2}{*}{ Extração vegetal } & Pronaf B & 4.743 & 31.596 & 2.677 & 4.228 & $\mathbf{4 3 . 2 4 4}$ \\
& Pronaf V & 731 & 25.755 & 2.983 & 4.996 & $\mathbf{3 4 . 4 6 5}$ \\
\hline
\end{tabular}

Fonte: IBGE (2019)

As receitas dos agricultores familiares pronafianos do Matopiba podem ser observadas, pelos tipos de receitas principais, na tabela 9. No caso dos agricultores familiares do Pronaf B, a principal fonte de receita é aquela proveniente de aposentadorias e pensões. Para esses agricultores, a receita proveniente dessa fonte é muito superior à proveniente da segunda fonte, em termos de valor total, qual seja a produção animal e de produtos derivados. Especificamente no Maranhão, a participação da receita de aposentadorias e pensôes sobre a receita total é bastante elevada. A terceira principal fonte de receita para os agricultores do Pronaf $\mathrm{B}$ consiste nos recursos provenientes de programas governamentais.

No caso dos agricultores familiares enquadrados no Pronaf V, a principal fonte de receita é representada pela produção animal e produtos derivados; a segunda é representada pela venda de produtos vegetais; e a terceira, por receitas de aposentadorias e pensóes.

Deve-se destacar a concentração da produção e das receitas provenientes da produção animal e vegetal nos estabelecimentos agropecuários do Matopiba. Observa-se, como exemplo, a receita proveniente da produção vegetal dos agricultores familiares pronafianos $(\mathrm{B} \mathrm{e} \mathrm{V})$ no Tocantins, R \$ 75,39 milhôes, e animal, R \$ 452,33 milhôes (tabela 9). Na comparação com os valores das receitas provenientes desses mesmos produtos dos agricultores não familiares no Tocantins (todos os municípios desse estado fazem parte do Matopiba) - respectivamente, $\mathrm{R}$ \$ 3,02 bilhôes e $\mathrm{R}$ \$2,26 bilhôes -, tem-se a dimensão da concentração da produção nesse estado (nos outros estados do Matopiba, a situação não é diferente).

Sobre isso, Alves e Souza (2015) afirmam que a principal característica da estrutura agrícola do Matopiba é a concentração da produção. Ao avaliarem os estabelecimentos agropecuários da regiáo em função das classes de renda, com base em dados do censo agropecuário de 2006, constataram que a grande maioria dos estabelecimentos rurais, quase $80 \%$, estava enquadrada na classe de zero a dois salários mínimos (SMs), auferindo apenas 5,22\% da renda bruta. Ao considerarem que em cada estabelecimento residam cinco pessoas, a renda per capita média resultante era de, à época, apenas $0,12 \mathrm{SM}$ - quase 1 milhão de pessoas muito pobres. No outro extremo, 1.020 estabelecimentos obtinham uma renda superior a 200 SMs mensais e se apropriavam de quase $60 \%$ da renda agrícola regional. 
Os dados do censo agropecuário de 2017 para o Tocantins apresentam uma realidade pouco distinta da relatada por Alves e Souza (2015). A receita proveniente da produção animal e vegetal dos estabelecimentos não familiares no estado é aproximadamente dez vezes superior àquela dos estabelecimentos familiares pronafianos (a maioria dos estabelecimentos familiares no Tocantins é pronafiana - tabela 6).

TABELA 9

Matopiba: valor da receita por tipo das principais receitas do estabelecimento, segundo a agricultura familiar pronafiana (2017)

(Em R\$ 1 mil)

\begin{tabular}{lcrrrrr}
\hline Categoria & Categoria agricultura familiar & Bahia & Maranhão & Piauí & Tocantins & Total do Matopiba \\
\hline $\begin{array}{l}\text { Produção do estabelecimento - } \\
\text { produtos vegetais }\end{array}$ & Pronaf B & 6.475 & 45.628 & 2.154 & 8.768 & 63.025 \\
\hline $\begin{array}{l}\text { Produção do estabelecimento - animais } \\
\text { e produtos derivados }\end{array}$ & Pronaf V & 48.946 & 48.272 & 4.255 & 66.623 & 168.096 \\
\hline $\begin{array}{l}\text { Produção do estabelecimento - produtos } \\
\text { da agroindústria }\end{array}$ & Pronaf B & 88.809 & 155.083 & 21.679 & 102.866 & $\mathbf{3 6 8 . 4 3 7}$ \\
\hline $\begin{array}{l}\text { Receitas do produtor - recursos de } \\
\text { aposentadorias ou pensões }\end{array}$ & Pronaf B & 10.790 & 37.656 & 2.146 & 15.557 & $\mathbf{6 6 . 1 4 9}$ \\
\hline $\begin{array}{l}\text { Receitas do produtor - rendas obtidas } \\
\text { em atividades fora do estabelecimento }\end{array}$ & Pronaf B & 337.500 & 490.544 & 127.995 & 185.541 & $\mathbf{1 . 1 4 1 . 5 8 0}$ \\
\hline $\begin{array}{l}\text { Receitas provenientes de programas dos } \\
\text { governos (federal, estadual ou municipal) }\end{array}$ & Pronaf V & 20.393 & 52.540 & 11.287 & 54.948 & $\mathbf{1 3 9 . 1 6 8}$ \\
\hline
\end{tabular}

Fonte: IBGE (2019).

\section{CONSIDERAÇÕES FINAIS}

Neste breve ensaio, buscou-se analisar a agricultura familiar nos estados do Matopiba e diagnosticar as características dos agricultores familiares contratantes do Pronaf na regiáo com base em dados do censo agropecuário de 2017.

Evidenciou-se a grande presença de estabelecimentos familiares no conjunto total de estabelecimentos agropecuários na região. Dos estabelecimentos familiares, a maioria participa do Pronaf. No conjunto, aproximadamente $79 \%$ são enquadrados na categoria de produção familiar, ao passo que no Brasil essa relação é de aproximadamente $76 \%$. No interior da região, a maior ou menor presença relativa da agricultura familiar, entretanto, é bastante variável.

Ali, a maioria dos estabelecimentos realiza atividades de produção variadas, envolvendo a criação animal e a produção vegetal em um mesmo local. O valor da produção animal dos agricultores familiares do Matopiba concentra-se em animais de grande porte (principalmente bovinos), fenômeno particularmente evidente no Tocantins. Já em termos da produção vegetal, o valor da produção se concentrou em espécies temporárias, como soja, milho, algodão e outras, destacando-se também o resultado do valor da produção de itens provenientes de extração vegetal para a produção vegetal da agricultura familiar da região.

Com relaçáo às receitas dos estabelecimentos e dos produtores, as provenientes da pecuária e dos derivados da produçáo animal constituem a principal fonte em termos de valor agregado. Na sequência, os recursos vindos de aposentadorias e pensóes e, em terceiro lugar, da venda de produtos de origem vegetal. 
Quanto às categorias de maiores gastos da produção, os três principais itens são compra de animais; compra de sal, ração e outros insumos para a criação animal; e salários, novamente evidenciando a importância da criaçáo animal para a agricultura familiar. Existem, claramente, diferenças na composição dos gastos dos agricultores familiares do Matopiba. Preliminarmente, observou-se que há indícios do maior grau de especialização na produção animal dos agricultores familiares de Tocantins e Maranhão com relação aos da Bahia e do Piauí.

No universo avaliado, a grande maioria dos agricultores familiares nos municípios do Matopiba é participante do Pronaf, em especial do B. Tanto assim que parte significativa da produção animal, em todas as categorias dos agricultores familiares do Matopiba, é proveniente de estabelecimentos que receberam crédito do Pronaf. Todavia, apesar de a maioria dos estabelecimentos fazer parte do Pronaf B, a maior parte do valor da produção animal é realizada por estabelecimentos do Pronaf V.

Com relação às lavouras permanentes, em todos os estados da região, o valor de sua produção em 2017 foi concentrado entre os agricultores familiares crediários do Pronaf V, especialmente no caso baiano. Dada a característica das lavouras permanentes de variabilidade de produção, e consequentemente da respectiva renda, os agricultores mais voltados às lavouras permanentes tendem a uma maior variabilidade de renda que nas lavouras temporárias; daí recorrerem ao Provaf V.

No caso das lavouras temporárias, boa parte do valor da produção dos agricultores familiares pronafianos do Matopiba nos estados de Bahia, Maranhão e Piauí concentra-se no enquadramento do Pronaf B, com exceção do Tocantins. Em paralelo, no caso da produção hortícola e do extrativismo vegetal, comparativamente, o valor da produção está mais igualmente distribuído entre os agricultores familiares participantes das duas modalidades do programa.

Ainda em termos de modalidades, para os agricultores familiares do Pronaf $\mathrm{B}$, a principal fonte de receita está nas aposentadorias e pensóes, notadamente no caso maranhense. Em termos de valor total, as receitas da produçáo animal e de produtos derivados, além dos recursos provenientes de programas governamentais, são também importantes. Já para os produtores familiares usuários do Pronaf $\mathrm{V}$, a principal fonte de receita é representada pela produção animal e produtos derivados, secundada pela venda de produtos vegetais e pelas receitas de aposentadorias e pensóes.

Igualmente, deve-se destacar a concentração da produção e das receitas provenientes da produção animal e vegetal nos estabelecimentos agropecuários do Matopiba, havendo também indícios de divergência de renda dos agricultores familiares pronafianos da região $v i s-\grave{a}$-vis seus correspondentes da agricultura tipificada não familiar.

Este artigo teve por intuito fazer uma análise a partir de uma única fonte de dados, os do Censo Agropecuário 2017. A caracterização aqui proposta pode ser expandida em outros estudos com a utilização de fontes de dados diversos, como os do Banco Central e de outras instituiçóes envolvidas com a operacionalização do Pronaf (Bancos do Brasil e do Nordeste, por exemplo).

Inúmeros objetivos analíticos podem ser propostos para aprofundar a incipiente caracterização aqui apresentada, como o de analisar as diferenças na composição dos gastos dos agricultores familiares do Matopiba em função do grau de especialização do agricultor (produçáo animal ou vegetal etc.) e/ou do padrão tecnológico da atividade produtiva do estabelecimento, da escala de produção etc. Adicionalmente, pode-se analisar a agricultura 
familiar, e/ou o Pronaf, no Matopiba em diferentes recortes regionais - por exemplo, no nível de mesorregióes ou de microrregióes. Outra possibilidade é efetuar uma análise comparativa do perfil do pronafiano do Matopiba com aquele da região Sul.

Essas e outras possibilidades de análise são importantes para se conhecer melhor a realidade da agricultura familiar nesse recorte territorial que tem adquirido significativa notoriedade na última década. Este estudo, pautado pela caracterização dos agricultores familiares da região com base em poucas variáveis, demonstra realidades bem distintas nos estados componentes do Matopiba. Compreender as distinçóes existentes auxiliará o Estado na constante missão de aprimorar as políticas públicas, entre as quais o Pronaf, voltadas para os agricultores familiares.

\section{REFERÊNCIAS}

ALVES, E.; SOUZA, G. da S. Matopiba pelo censo agropecuário 2006. In: BOLFE, É. L. (Coord.). Relatório técnico: organização de um banco de dados geoespaciais e elaboração de planos de informaçóes sobre aspectos físico-bióticos, de logística e infraestrutura, conservação, unidades de paisagem e aptidão, expansão e intensificação agrícola da região do Matopiba. Campinas: Embrapa, 2015.

ALVES, M. O. et al. Beneficiários do Pronaf B no Semiárido brasileiro: perfil socioeconômico, condiçōes materiais de produção e estratégias de reprodução. In: MATA, D. da; FREITAS, R. E.; RESENDE, G. M. (Ed.). Avaliação de políticas públicas no Brasil: uma análise do Semiárido. 1. ed. Brasília: Ipea, 2019. 404 p. v. 4.

BOLFE, É. L. et al. Matopiba em crescimento agrícola: aspectos territoriais e socioeconômicos. Revista de Política Agrícola, v. 25, n. 4, p. 38-62, out./dez. 2016.

CASTRO, C. N. de. Sobre a agricultura irrigada no Semiárido: uma análise, histórica e atual, de diferentes opçóes de política. In: MATA, D. da; FREITAS, R. E.; RESENDE, G. M. (Ed.). Avaliaçáo de políticas públicas no Brasil: uma análise do Semiárido. 1. ed. Brasília: Ipea, 2019. 404 p. v. 4.

CASTRO, N. de. Expansão rodoviária e desenvolvimento agrícola dos cerrados. In: HELFAND, S. M.; REZENDE, G. C. de. (Org.). Regiáo e espaço no desenvolvimento agrícola brasileiro. Rio de Janeiro: Ipea, 2003. p. 213-243.

FREITAS, R. E. O Pronaf no Semiárido: diagnósticos do programa e observaçóes para o futuro. In: MATA, D. da; FREITAS, R. E.; RESENDE, G. M. (Ed.). Avaliaçáo de políticas públicas no Brasil: uma análise do Semiárido. 1. ed. Brasília: Ipea, 2019. 404 p. v. 4.

FREITAS, R. E.; MACIENTE, A. N. Mesorregiōes brasileiras com expansão de área agrícola. Radar: Tecnologia, Produção e Comércio Exterior, n. 41, p. 1-18, 2015.

IBGE - INSTITUTO BRASILEIRO DE GEOGRAFIA E ESTATÍSTICA. Censo agropecuário 2017: resultados definitivos. Rio de Janeiro: IBGE, 2019.

MELLO, F. H. de. O crescimento agrícola brasileiro dos anos 80 e as perspectivas para os anos 90. Revista de Economia Política, v. 10, n. 3, p. 23-30, jul./set. 1990.

MOREIRA, A. R. B.; PAEZ, M. Medindo a produtividade agrícola regional com efeito vizinhança. In: HELFAND, S. M.; REZENDE, G. C. de. (Org.). Regiáo e espaço no desenvolvimento agrícola brasileiro. Rio de Janeiro: Ipea, 2003. 
NOBRE, P. et al. O paradigma da abundância para o desenvolvimento sustentável do Nordeste Semiárido: uma análise ex ante do papel da geração fotovoltaica distribuída. In: MATA, D. da; FREITAS, R. E.; RESENDE, G. M. (Ed.). Avaliaçáo de políticas públicas no Brasil: uma análise do Semiárido. 1. ed. Brasília: Ipea, 2019. 404 p. v. 4.

SOBEL, T. F.; XAVIER, L. F. Desenvolvimento territorial no Semiárido: uma avaliação a partir da experiência do polo Petrolina-Juazeiro. In: MATA, D. da; FREITAS, R. E.; RESENDE, G. M. (Ed.). Avaliação de políticas públicas no Brasil: uma análise do Semiárido. 1. ed. Brasília: Ipea, 2019. 404 p. v. 4.

SOTERRONI, A. C. et al. Modelagem de mudanças de uso da terra no Brasil: 2000-2050. In: VIEIRA FILHO, J. E. R.; GASQUES, J. G.; CARVALGO, A. X. Y. de. (Ed.). Agricultura, transformaçáo produtiva e sustentabilidade. Brasília: Ipea, 2016. 